\title{
7TH ANNUAL PUBLIC HEALTH CONFERENCE 2016 AT HEALTH SERVICES ACADEMY: EXPERIENCES IN THE FIELD OF PUBLIC HEALTH AND WAY FORWARD
}

\author{
Neelam A Khan ${ }^{1}$, Saima Hamid ${ }^{2}$, Katrina Ronis ${ }^{3}$ \\ ${ }^{1}$ MSPH 1516 Student, Health Services Academy, Islamabad \\ ${ }^{2}$ Associate Professor, Health Services Academy, Islamabad \\ ${ }^{3}$ Associate Professor,Adjunct Faculty, Health Services Academy, Islamabad \\ Correspondence: NeelamA Khan.Email: neelamkhan16@yahoo.com
}

\begin{abstract}
Background

Health Services Academy held its 7th Annual Public Health Scientific Conference in December 2016 in Islamabad, Pakistan. The theme was Sustainable Development Goals (SDGs) in Health: Collaborating for Prosperity. Over seven hundred international and national public health specialists attended to share research initiatives, build partnerships and strengthen networks. Post-conference online survey was emailed to all participants to facilitate a more structured feedback and hence evaluation of the two day event.

Methods: An online instrument was developed using the "Survey Monkey" template. Total participants $(n=757)$ were invited to complete the online survey which consisted of five sections: Likert scales were utilised to ascertain how "informative" the conference was to the participants. Comment boxes were provided for each section to collect qualitative responses. The quantitative data was collated by Survey Monkey and presented in percentages. Manual thematic analysis was utilised for the qualitative data.

Results: The final online surveys emailed was seven hundred and four and of these just over two thirds (67\%) were opened and $33 \%(n=230)$ were unopened. The latter emails may have been in the "spam" box or not opened. Of the opened surveys $(n=474)$ nearly two hundred were completed and emailed back, a response rate of forty two percent $(n=199)$. The quantitative data revealed that the majority of respondents $(75 \%)$ found the plenary sessions to be'very informative 'and approximately half of the respondents considered the scientific sessions to be 'extremely informative' or 'very informative'. With respect to how useful the conference was to the participant's field of public health, almost half (44\%) responded 'very useful and over a third $(34 \%)$ responded 'extremely useful'. The top three themes recommended for the 2017 Conference included Nutrition; Non-Communicable Diseases and Mental Health and Sustainable Development Goals.

Conclusion: The majority of survey respondents agreed that the conference was a success and the theme was useful in their own field of public health. Several themes for the 2017 conference were provided with a focus on nutrition the most popular.
\end{abstract}

Keywords: Public Health, Sustainable Development Goals, evaluation and online survey

\section{Introduction}

Health Services Academy (HSA)was established in 1988 as an in-service training institute for the government health sector andhas evolved over the years into a premier institution of public health. It continues to function as an autonomous organisation under the 'Ministry of National Health Services, Regulations \& Coordination', Pakistan.Its mission is to establish itself as a regional centre of excellence in public healthand support the vision of the World Health Organisation.

Since 1988 more than eight hundred students have completed graduate level studies in public health from the Academy.A Doctor of Philosophy (PhD) program was inaugurated in 2012 and currently there are 19doctorate students. The HSAAlumni are working in academia, research, policy making, and management in the private and public sector nationally and internationally. In 2010, the Academy undertook the initiative to organize annual public health conferences which have attractedpublic health professionals across the country and from abroad.Each year the conference theme is set in accordance with Pakistan's priority public health issues.

In December 2016, the 7th Annual conference's theme "Sustainable Development Goals (SDGs) in Health: Collaborating for Prosperity" focused on a world in which partnerships and prosperity are at the forefront for achievement of sustainable development in health. The SDGs are a set of 17 global goals which were adopted by the UN Member States at the 
"Sustainable Development Summit" on 25th September, 2015. Pakistan adopted the SDGs in February 2016 through a parliamentary resolution that was passed unanimously. Prioritizing health is resonated in the "Pakistan Vision 2025" and "National Health Vision 2016-25".

The 2016 conference provided a platform for over 700health experts, allied disciplines and students to communicate and share knowledge, experiences and best practices towards achieving the SDGs for Health. Additionally, it promoted discussion on identifying synergies and partnerships for building collective commitment and harnessing resources for development.

The two day event provided an opportunity for public health colleagues to network and also attend theplenary and scientific sessions.A total of 39 papers were presented at the ten scientific sessions by international and national speakers. Eleven stalls were set up and included International NonGovernment Organisations (INGOs), NonGovernment Organisations (NGOs), local health informatics companies and academic book vendors.

The 2016 conference featured new elements: the 'comment wall' and 'photo frame' pledging a commitment to fulfilling the SDGs. In the past an informal feedback mechanism facilitated feedback from the conference participants. To promote and support the importance of monitoring and evaluationin public health,an online evaluation survey was emailedto all participants of the Academy's 7th Annual Public Health Conference. The main aim of this online survey was to assess how informativethe content of the conference was and to seek themes for the 2017 conference.

\section{Methodology:}

The research aim was "To ascertain how informative the 7th Annual Public Health Conference was forparticipants?" The research method utilised was an online survey with a quantitative and qualitative approach (i.e. mixed method). There were fivephases applied to the evaluation process: Selection of the Participants; Development of the Instrument; Surveying the Participants; Data Collection and lastly Data analysis and interpretation.

\section{First Phase:}

Selection of the Study Participants

A mailing list of all registered conference participants $(n=757)$ was obtained from the "Conference Secretariat". These participants included academics, students and company representatives. Individualemail addresses were checked for correct formatting.Some of the public health professionals registered for the conference did not attend the conference but were included in the evaluation.

\section{Second Phase:}

Development of the Survey Instrument

An online instrument was developed using the
"SurveyMonkey" template. This was piloted with four faculty members of the Academy. The online survey consisted of five sections pertaining to the conference sessions. A Likert scale of five levels were utilised to ascertain how "informative" the conference sessions were for the participants e.g. 'extremely informative', 'very informative', 'moderately informative', 'not at all informative' and 'did not attend'. Comment boxes were provided for each section to collect qualitative responses. A limitation of the online survey instrument was the absence of demographic data fields e.g. Age/Gender/Position/Province etc.

\section{Third Phase:}

Surveying the participants

The online survey was emailed to all registered participants $(n=757)$ however fifty two emails bounced. Of the remaining emails $(n=705)$ one participant opted out. Of the remaining 704 participants $67 \%(n=474)$ were opened their survey and $33 \%(n=230)$ did not open their survey. The unopened emails and hence survey may have remained in the participants "spam" box, were not received or ignored.

\section{Fourth Phase:}

\section{Data Collection}

The online survey was emailed out with an introduction to the survey and that all data would be treated confidentially. Weekly reminders were emailed to the participants to respond to the survey. This continued for four weeks.

\section{Fifth Phase:}

Data analysis and interpretation

Data from the online survey quantitative sections were automatically collated by SurveyMonkey(i.e. for the Likert scale responses) and presented in graphical format in percentages. Thematic analysis was undertaken manually for the qualitative data comments.

\section{Results:}

The onlinesurvey was emailed to seven hundred and fifty seven $(n=757)$ participants. Fifty two emails bounced leaving a total of seven hundred and five $(n=705)$ emails sent. From this amount four hundred and seventy four $(n=474)$ participants opened their survey email and one hundred and ninety nine $(n=199)$ responded (opened) and emailed back the survey, a forty two percent response rate $(42 \%)$. However two hundred and thirty $(n=230)$ emails remained unopened. These emails may have been in the participants "spam" box and not checked.

\section{Plenary sessions:}

The theme for the first plenary session was "Global Agenda for Sustainable Health Solutions", and included three presentations. Overall, at least two thirds of respondents found the first plenary 'very informative', especially the "Sustainable Solutions for Sustainable Development presentation". A small minority stated it was 'not informative' as shown in 
Table 1: Informative levels of Plenary presentations on "Global Agenda for Sustainable Health Solutions"

\begin{tabular}{|l|l|l|l|}
\hline $\begin{array}{l}\text { Responses } \\
n=190\end{array}$ & $\begin{array}{l}\text { Sustainable Solutions for } \\
\text { Sustainable Development }\end{array}$ & $\begin{array}{l}\text { Gender, Health \& } \\
\text { Population Matters }\end{array}$ & $\begin{array}{l}\text { Service delivery } \\
\text { improvement for move } \\
\text { towards UHC }\end{array}$ \\
\hline $\begin{array}{l}\text { Very } \\
\text { informative }\end{array}$ & $80 \%$ & $74 \%$ & $67 \%$ \\
\hline $\begin{array}{l}\text { Not } \\
\text { informative }\end{array}$ & $4 \%$ & $8 \%$ & $8 \%$ \\
\hline $\begin{array}{l}\text { Did not } \\
\text { attend }\end{array}$ & $16 \%$ & $18 \%$ & $25 \%$ \\
\hline
\end{tabular}

The second plenary session's theme was "CrossSector Partner Engagement in Building Sustainable Health Systems". The majority of respondents found the three presentations almost equally 'very informative' (average 71\%). Those that found the presentations 'not informative' were on average $7 \%$, with NCDs and Nutrition: Policies \& Actions the least informative (9\%) as shown in Table 2.

Table 2: Informative levels of Plenary presentations on "Cross-Sector Partner Engagement in Building Sustainable Health Systems"

\begin{tabular}{|l|l|l|l|}
\hline $\begin{array}{l}\text { Responses } \\
n=186\end{array}$ & $\begin{array}{l}\text { NCDs and Nutrition: } \\
\text { Policies \& Actions }\end{array}$ & $\begin{array}{l}\text { SDGs - Health in } \\
\text { all Policies }\end{array}$ & $\begin{array}{l}\text { Development of Indicators } \\
\text { for SDGs }\end{array}$ \\
\hline $\begin{array}{l}\text { Very } \\
\text { informative }\end{array}$ & $70 \%$ & $73 \%$ & $71 \%$ \\
\hline $\begin{array}{l}\text { Not } \\
\text { informative }\end{array}$ & $9 \%$ & $8 \%$ & $5 \%$ \\
\hline $\begin{array}{l}\text { Did not } \\
\text { attend }\end{array}$ & $21 \%$ & $19 \%$ & $24 \%$ \\
\hline
\end{tabular}

There were a total of forty one $(n=41)$ comments received on the plenary sessions. Of these almost halfwere 'positive' comments such as "good work", "clearly presented", "excellent" and "very helpful". There wereless than a quarter that focused on aspects to improve upon such as "...the local context not included", "...more elaboration needed" and "Question/Answer sessionswere needed".

Scientific Sessions:

There were ten scientific sessions with responses on seven sessions that were conducted on Day 2. Alist of the sessions is shown in Box 1.

BOX 1: Scientific Session Themes

1. Role of Family Planning in achieving SDGs

2. Nutrition

3. International Health Regulations/Global Health Security Agenda

4. Maximising synergies between Maternal Nutrition and Birth Spacing

5. Innovative approaches to raise awareness and improve service provision in Reproductive Maternal and New-born Health in KP

6 Burden of Disease

Approximately two thirds $(n=178)$ found the sessions 'very informative'. The most informative session was on the "Nutrition"session (67\%); the least informative was the session on "Maximizing synergies between Maternal Nutrition and Birth Spacing"(8\%). A comparison of how informative the sessions were is shown in Figure 1.

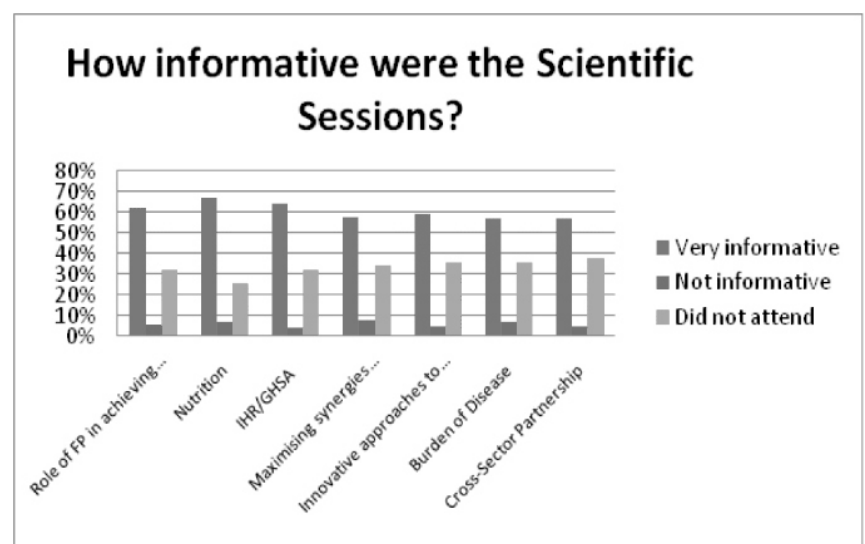

Figure 1: How informative were the Scientific Sessions?

There were thirty ninewritten comments of which a third $(n=13)$ were 'positive' remarks such as "amazing" and "highly informative". Eleven $(n=11)$ constructive comments related to some logistical issues and the quality of some presentations for example "...some multimedia not clear" and "...actual data not included". 
Usefulness of Conference:

Almost half of the respondents (43\%) found the conference to be 'very useful' with respect to their personal field of public health. Just over a third (35\%) responded as 'extremely useful' and $16 \%$ found it to be 'moderately useful' as shown in Figure 2.

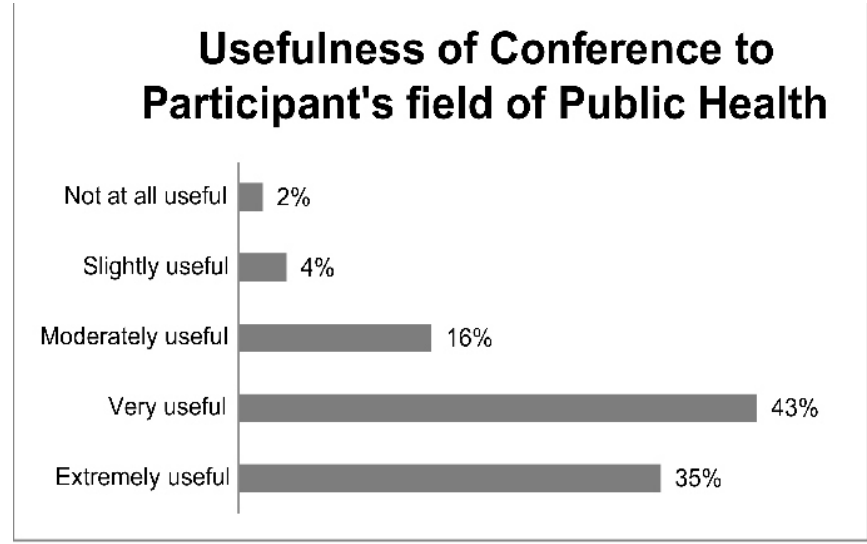

Figure 2: Usefulness of Conference to Participants

Twelve comments were provided of which a third $(n=4)$ were 'positive' remarks such as "inspiring and motivating" and "relevant to Pakistan perspective". Two constructive comments focused on improving thequality of some presentations and some posters.

Learning Environment:

Overall, the learning environment of the conference was perceived to be 'very good' by almost half (44\%) of the respondents; 'excellent' by $32 \%$ and 'arrentahle' hv 17\%as shnwn in Finure 3

\section{Learning Environment of Conference}

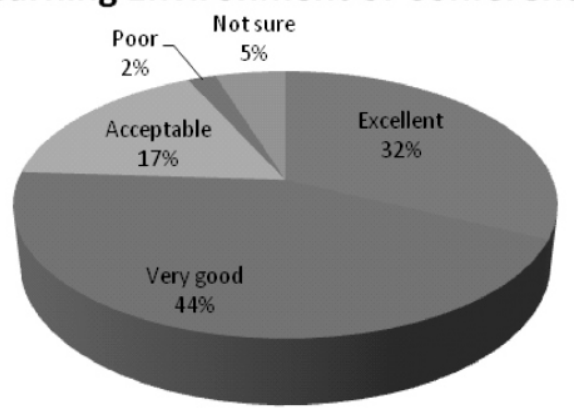

Figure 3: Learning Environment of Conference Eleven comments were received and almost half provided positive feedback such as "opportunities to learn" and "outstanding". Constructive comments $(n=3)$ included"...students should begiven the opportunity to present research" and attention needed for some of the seating arrangements.

Logistics of conference:

Over half $(54 \%)$ of the participants were 'satisfied' with the logistics of the conference. About a third (34\%) was 'very satisfied' and a small proportion expressed non-satisfaction (7\%), as shown in Figure

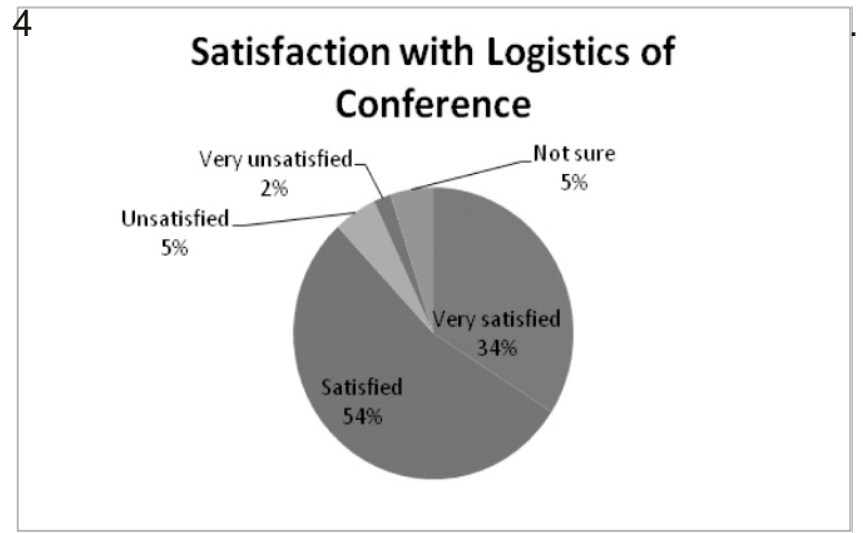

Figure 4: Satisfaction with logistics of Conference

Eleven comments werereceived, of which the majority $(n=8,73 \%)$ were 'constructive feedback in that there was a need to address the"lack of communication between administration and participants", "poor parking arrangements", "water bottles not available for panel" and "poster certificate not received". One participant stated "good work".

Suggestions of themes for the 2017Conference:

Respondents provided a variety of themes for the next conference in 2017. However, the top five themes included:

1. Nutrition and related topics ( Food security, Obesity)

2. NCDs and Mental Health (across the life-course)

3. SDGs (Monitoring and Progress)

4. Adolescent Health

5. Gender related issues (Equity, Empowerment, Violence against women); and $\mathrm{SRH}$ issues (across the life-course)

Table 3: Suggested Themes for the 2017 Annual Public Health Scientific Conference Final comments and suggestions:

\begin{tabular}{|l|l|l|}
\hline Themes for 2017 Conference & $\begin{array}{l}\text { No. of Respondents } \\
\text { (total = 156) }\end{array}$ & $\begin{array}{l}\text { Percentage of } \\
\text { Respondents }\end{array}$ \\
\hline Nutrition \& related topics & 18 & $12 \%$ \\
\hline NCDs \& Mental health & 16 & $10 \%$ \\
\hline SDGs & 15 & $10 \%$ \\
\hline Adolescent Health & 12 & $8 \%$ \\
\hline Gender \& Health & 10 & $6 \%$ \\
\hline
\end{tabular}

For this section seventy two commentswere received. About two thirds $(n=45)$ provided supportive comments related to the overall success of the conference for example "...excellent arrangements", "... beneficial to students", "...expect even better for the 8th conference" and "best conference so far!" One respondent recommended more international speakers. Other comments $(n=20)$ were related to the overall logistics and aspects to consider for the next conference given the ever increasing participants, which mainly focused on the need for a bigger venue and more than two days required. Other constructive 
comments included "... more time for the question/answer sessions" and "...softcopies of all presentations for the participants..."

\section{Discussion}

The primaryaim of the 7thAnnual Public Health Scientific Conference of Health Services Academywasto provide a platform for public health specialists to share research, evidence-based dataand concepts at a national and international level according to the SDG theme. For the 2016 event a more formal evaluation process was undertaken via the online survey tool "SurveyMonkey" to ascertain how informative the conference was and to receive constructive feedback for the 2017 conference.

Those participants who received the emailed survey was four hundred and seventy four $(n=474)$ of which $42 \%$ responded. A meta-analysis on response rates for Internet based or web based surveys revealed that the average response rates ranged from $34-40 \%$ and an acceptable response rate varies between $25-30 \%$. For the 2017 conference, participants will be informed throughout the conference that an online survey will be sent from the Conference Secretariat to increase the number of participants who open the survey and who also check in their spam box.

For the 2016 Conference Secretariat many aspects of the main findings were supportive and constructive in terms of planning for the 2017 event. The main data revealed that the plenary and scientific sessions were deemed to be very informative by at least two-thirds of the respondents, and in some cases up to three quarters. The majority of the online survey respondents found the conference useful to their individual field of public health and found the learning environment conducive.

Overall, the logistics of the conference were found to be satisfactory by most of the respondents. Seating arrangements and technical glitches were highlighted as areas of improvement for the 2017 conference. Suggestions for themes for the forthcoming conference focused on nutrition and SDGs, however there was also an interest related to adolescent/youth health, NCDs and mental health and gender related topics. Additionally, increasing the duration of the conference was suggested by some participants.

Regarding a change in venue which was suggested by some participants, the Health Services Academy prides itself on undertaking this annual event at its picturesque premises; however due to the overwhelming number of participants every year, adequately accommodating all of them in the scientific sessions is a challenge and an area for improvement. Providing participants with soft copies of presentations of speakers is a trend at many conferences and will be considered keeping in mind intellectual property rights.

Some participants mentioned reducing the number of concurrent sessions, as some sessionswere of interest to participants and a choice had to be made on which one to attend.

Sharing the main findings from the online survey supports the Academy's quest to disseminate research findings to study participants. It is acknowledged that the 2016 online survey can be improved upon for the 2017 conference and greater communication to the participants regarding its usage as an evaluation tool.

\section{Conclusion}

According to the online survey evaluation the 2016 conference was informative and met participants' needs with respect to their field of public health. This may be attributed to theearly and extensive planning that was undertaken by the Conference Secretariat. The primary aim was achieved and local public health professionals' needs were generally met. Engaging international speakers was generally appreciatedand most of the participants were satisfied with how informative the conference content was and how supportive thelearning environment was. Using an online survey for evaluation has many positive attributes and is an instrument that will be reconsidered for the 2017 conference.

\section{References}

1. Health Services Academy, Government of Pakistan. Accessed online on 1 January 2017 through http://www.hsa.edu.pk/

2. National Health Services regulation and Coordination. Accessed online on 1 January 2017 through http://www.nhsrc.gov.pk/

3. World Health Organization. Accessed online on 1 January 2017 through http://www. who.int

4. Sustaiable Development Goals. Accessed online on 1 January 2017 through http://www.un.org/sustainabledevelopment/sust ainable-development-goals/

5. United Nations of Pakistan. Accessed online on 1 $\mathrm{J}$ a n u a r y 2017 t h r o u g h http://www.un.org.pk/pakistans-challengessustainable-development-goals-2015-2030/

6. Planning Commission of Pakistan. Accessed online on 1 January 2017 through http://pc.gov.pk/web/vision

7. Ministry of Planning Development and Reforms. Accessed online on 1 January 2017 through http://www.mopdr.com/vision/uploads/vision/pa kistan_vision2025.pdf

8. Sarantakos S. Social research. Palgrave Macmillan; 2012.

9. SurveyMonkeys.Accessed online on 1 January $2017 \quad t \mathrm{~h} \mathrm{rou} \mathrm{g} \mathrm{h}$ http://www.SurveyMonkey.com/Official-Site

10. Cook C, Heath F, Thompson RL. A meta-analysis of response rates in web-or internet-based surveys. Educational and psychological measurement. 2000;60(6):821-36. 